\title{
VIDA-Nursing v1.0: immersive virtual reality in vacuum blood collection among adults*
}

\author{
Valtuir Duarte De Souza-Junior ${ }^{1,2}$ \\ (1) https://orcid.org/0000-0002-8660-9743 \\ Isabel Amélia Costa Mendes ${ }^{1}$ \\ (D) https://orcid.org/0000-0002-0704-4319 \\ Romero Tori ${ }^{3}$ \\ (D) https://orcid.org/0000-0001-9381-9565 \\ Leonardo Prates Marques ${ }^{1,4}$ \\ (1D) https://orcid.org/0000-0003-3544-0818 \\ Felipe Kenzo Kusakawa Mashuda ${ }^{3,5}$ \\ (D) https://orcid.org/0000-0002-2075-3259 \\ Leonardo Akira Fattore Hirano ${ }^{3}$ \\ (1) https://orcid.org/0000-0002-1559-9250 \\ Simone De Godoy \\ (iD) https://orcid.org/0000-0003-0020-7645
}

Objective: to develop and validate the first immersive virtual reality simulation addressing vacuum blood collection in adult patients - VIDA-Nursing v1.0. Method: methodological study to validate 14 steps of the vacuum blood collection procedure in adults, designed to develop the immersive virtual reality simulator VIDA-Nursing v1.0. It was assessed by 15 health workers and 15 nursing undergraduate students in terms of visual, interactive, movement simulation reality, teaching and user-friendly aspects. Results: the workers considered $79.6 \%$ of the items to be valid, while the students considered $66.7 \%$ of the items valid; most of the demands can be implemented in the system by improving future versions. Conclusion: the simulator was considered a promising and innovative tool to teach vacuum blood collection in adults as it can be combined with other resources currently used to introduce this topic and technique in the education of undergraduate nursing students.

Descriptors: Virtual Reality; Simulation; Simulation Training; Blood Specimen Collection; Technological Development and Innovation Projects; Nursing.

\section{How to cite this article}

Souza-Junior VD, Mendes IAC, Tori R, Marques LP, Mashuda FKK, Hirano LAF, Godoy S. VIDA-Nursing v1.0: immersive virtual reality in vacuum blood collection among adults. Rev. Latino-Am. Enfermagem. 2020;28:e3263. [Access ‘_f_; ]; Available in: DOI: http://dx.doi.org/10.1590/1518-8345.3685.3263. 


\section{Introduction}

Peripheral venipuncture is defined as the insertion of devices through a peripheral vein to access one's bloodstream. It is a common, however, complex procedure performed in health care that demands competent workers to perform it ${ }^{(1-3)}$. A peripheral venipuncture is an essential stage in procedures for various purposes, among which intravenous therapy and the collection of blood samples for laboratory exams.

Inappropriately performing this stage may expose patients to site complications such as phlebitis, infiltration and/or hematoma and, when associated with incorrect procedures performed in other stages, complications may be systemic, such as thrombophlebitis and bloodstream infections, which are more frequently associated with the use of intravenous devices ${ }^{(1-2,4-7)}$.

A peripheral venous puncture inadequately performed may also compromise the results of laboratory exams, which is one of the major aspects to be continuously addressed by the staff in the preanalytical phase of blood collection ${ }^{(8)}$ and may reflect on improper conducts in a patient's treatment ${ }^{(9-11)}$.

There are many technologies to develop skills and competencies related to the collection of blood samples and peripheral venous catheterization that include conventional arm simulators, models with latex veins that can be attached with straps over a human arm, and non-immersive virtual reality simulators.

Various teaching institutions have increasingly incorporated the use of simulators in teaching strategies. Simulators can be used to develop technical skills, interpersonal relationships, promote specific competencies or problem-solving skills while various types of simulators and environments, including the virtual environment, are employed(12). In this context, virtual refers to environments or elements synthesized by digital devices with the possibility to be immaterially replicated ${ }^{(13)}$.

Technological development has enabled interaction between person-machine to become increasingly advanced, facilitating the development of more realistic virtual environments. From this perspective, virtual reality (VR) promotes interactive and motivating simulators. VR is an advanced interface generated by computer-performed applications, through which users interact in real-time, stimulating the senses with elements of a three-dimensional environment such as visualization, movement, hearing and/or touch(14).

VR simulations have proven to be feasible, as reported by recent international studies, with important results both to support human resources training and the treatment of patients. There are two clinical trials reporting results in the treatment of patients ${ }^{(15-16)}$ and five clinical trials addressing the training of human resources ${ }^{(17-21)}$. There are also other types of study designs conducted in the field of human resources training (22-23).

Fifteen meta-analyses report VR simulators intended to support the treatment of patients(24-38), while two other meta-analyses report its use in the training of human resources ${ }^{(39-40)}$. In general, the studies present promising results in the use of VR simulations. The field of training focused on medical procedures in the surgical field in general and in laparoscopic surgery, hysteroscopy, mastoidectomy, and sutures.

There is, however, little evidence presented in the literature regarding the use of VR simulations in the teaching of nursing and we believe this technology can contribute with innovations in the training of human resources in health, mainly specialties, in which, lack of knowledge and skills directly affects the safety and integrity of patients.

Hence, considering that peripheral blood collection is one of the first invasive procedures commonly taught during the training of human resources in nursing, we opted for developing an immersive virtual reality simulator applied to the context of vacuum blood collection in adult patients.

Therefore, this study's objective was to develop and validate the first immersive virtual reality simulation addressing vacuum blood collection in adult patients VIDA-Nursing v1.0.

\section{Method}

Study with methodological design to develop and validate the 14 stages of the vacuum blood collection procedure performed in adult patients using the immersive virtual reality simulator VIDA-Nursing v1.0. The name refers to VIDA-Odonto(41), which is built upon the environment VIDA (Virtual Interactive DistanceLearning on Anatomy). The study received approval from the Institutional Review Board at the University of São Paulo at Ribeirão Preto, College of Nursing (EERP-USP), under CAAE 63058516.8.0000.5393.

Criteria used to develop the simulator were based on evidence reported in the literature concerning the vacuum blood collection procedure in adult patients ${ }^{(8,42-43)}$. Given the technological complexity of developing an immersive virtual reality simulator to train individuals for an invasive procedure, basic requirements were established to be applied in the short term, to test and verify the system feasibility, to be later complemented at the medium and long terms. 
In total, 16 requirements were listed for the procedure to be performed in the short term, namely: 1- Apply tourniquet on patient's arm; 2- Clean the venipuncture site with cotton soaked with alcohol at 70\%; 3- Remove cap from needle; 4- Use non-dominant hand to secure the vein; 5 - Puncture the patient's vein with bevel facing upwards, at an oblique angle of $10^{\circ}$ to $30^{\circ}$, compatible with the vein's depth; 6- Introduce the vacuum tube into the adapter; 7-Verify that blood is flowing into the tube; 8- Release and remove the tourniquet from patient's arm; 9- Wait for the vacuum tube to be filled; 10- Remove the blood-filled tube from the adapter; 11- Homogenize the blood sample by making gentle inversion movement, from 5 to 10 times; 12 - Bring dry cotton near the site where needle is piercing the arm; 13- Remove the needle; 14- Place the cotton and compress the site; 15- Activate safety device to protect the needle; 16 - Place the intermediary device on the tray. Important to note that requirements 3 and 15 had not been included in the first version given the difficulty in reproducing these movements in a virtual environment, thus these will be implemented in the simulator's second version.

The team was composed of eight people working directly in the development of the first version of VIDANursing v1.0: one undergraduate nursing student, two electrical engineering graduate students, one mechanical engineer, one electrical engineer, and three nurses.

The following were used for storing, sharing, managing and developing the modeling and programming of the environment and virtual objects: Unreal 4.18 (Game Engine); Visual Studio Community 2017 (Image editor); Blender 2.79 (3D modeler); GitHub (Online project and version management service); Git for Windows 2.16.1, 64-bit (Local management of Projects and Versions); TortoiseGit 2.6.0, 64-bit for Windows (Graphical Interface for Git); Inventor - AutoDesk 2018 (3D CAD Modeler); AutoCad - AutoDesk 2018 (3D CAD Modeler). The programs were run on the equipment: Computer Dell model XPS 8920; Leap Motion (Gesture Sensor); Oculus Rift (-Head Mounted Display)+Touch Virtual Reality System (Control). The character used as a patient was a 3D model provided by Adobe ${ }^{\odot(44)}$ free of charge to create, manipulate, and animate virtual design projects.

Content Validity Index (CVI) was used to validate the simulator. The CVI of the individual items is calculated to measure the proportion of agreement among the panel of judges when assessing a measuring instrument. The calculation used for each item was $\mathrm{CVI}=$ number of responses $1+2$ divided by the total number of answers, considering a minimum agreement of $80 \%$ for each item assessed $^{(45-46)}$.
The form used to validate the simulator addressed the following: Visual, Interactive, Movement Simulation Reality, Teaching, and User friendliness aspects. The authors developed the form and three workers with clinical and teaching experience in the procedure addressed here, validated it both in terms of face and content validity.

After taking part in the simulation, the participants rated their level of agreement with the statements that concerned the items presented in the assessment form, on a Likert scale ranging from strongly agree, neither agree nor disagree, disagree and strongly disagree.

Face and content validation was conducted by two groups: group 1 was composed of 15 health workers who mastered the topic and the vacuum blood collection procedure performed in adult patients and were recruited for being professors of theoretical-practical courses addressing this content in the institution where data were collected, and; group 2 composed of 15 undergraduate nursing students who had already performed the vacuum blood collection procedure in a simulated situation. None of the participants in the groups had had any previous contact with this simulator.

Data were collected from October $16^{\text {th }}$ to $23^{\text {rd }}$ 2018. Each group was invited for the simulation in the VIDA-Nursing v1.0 simulator installed in the laboratory of the Grupo de Estudos e Pesquisas em Comunicação no Processo de Enfermagem - GEPECOPEn [Study and Research Group on Communication in the Nursing Process] at EERP-USP. The environment was prepared for the participants to receive information regarding the study, sign a free and informed consent form, take part in the simulation, and complete the forms concerning characterization and assessment of the simulator, so that, their performance could be assessed. The monitor screen was video recorded during the simulation to support analysis and clarify potential doubts regarding the participants' performance.

The theoretical framework used to support the development of the simulator was provided by Skinner. Skinner's study on operant conditioning behavior has been used in educational games, entertainment games, and virtual simulations used in teaching(47-49). Operant conditioning refers to an organism's response through differential reinforcement of successive approximations, in which a response generates a consequence, which affects the probability of it occurring again in the future ${ }^{(50)}$

Data were coded and typed twice in Excel spreadsheets and then exported and analyzed in SPSS (Statistical Package for Social Science) version 22.0. Descriptive statistics were used, including an analysis of frequency and percentage, and CVI with a minimum 
agreement of $80 \%$ among the items assessed. The participants' suggestions were also addressed to be implemented in the following versions.

\section{Results}

The workers' ages ranged from 22 and 53 years old, with an average of 32.7 years old, while most were women (80\%). About graduate programs, ten (66.7\%) had a specialization; nine (60\%) had a Master's degree; seven $(46.7 \%)$ had a Doctoral degree, and one (6.7\%) had attended a post-doctorate program. In terms of experience in vacuum blood collection, only one $(6.7 \%)$ reported no specific experience with the vacuum technique; $13(86.7 \%)$ had already collected blood samples using a vacuum tube in an adult anatomical dummy, and three (20\%) reported some experience using a virtual reality simulator. Among the experiences reported, one referred to entertaining games using a head-mounted display (HMD) and two reported using a Virtual IV ${ }^{\circledR}$ simulator as a teaching strategy.

The ages of the undergraduate nursing students ranged from 20 to 26 years old, 22.3 years old on average, while 11 were women (73.3\%). Concerning the undergraduate program, five $(33.3 \%)$ were from the Nursing Teaching Diploma program while 10 $(66.7 \%)$ were from the Bachelor's Nursing program. Regarding their previous experience with the vacuum blood collection procedure, 11 (73.3\%) had previously drawn blood samples using a vacuum tube from adult patients, 15 (100\%) had performed vacuum blood collection using an anatomical adult dummy, and eight $(53.3 \%)$ reported the use of a virtual reality simulator. The experiences reported with a virtual reality simulator included the use of entertaining games using HMD, while seven had used it in a teaching situation. Four of these had experienced IV ${ }^{\circledR}$ Virtual simulator addressing the subject at hand, two had experienced a virtual learning environment in the neonatal field, and one had used a car simulator provided in a driver training school.

The Content Validity Indexes obtained by the workers and college students in aspects presented by the VIDA-Nursing simulator v.1.0 were, respectively:

Visual Aspects - Q1- In general, the virtual objects have a realistic appearance (1.0 and 0.9$)$; Each of the following objects are realistic in regard to their appearance: Q2- Chair (1.0 and 0.8); Q3- Patient (1.0 and 0.9); Q4- Bench (0.9); Q5- Tray (0.9 and 0.8); Q6- Intermediary device (1.0 and 0.9); Q7- Needle (1.0 and 0.7); Q8- Dry cotton (0.9 and 0.7); Q9- Cotton soaked with alcohol (0.8 and 0.5); Q10- Tourniquet (1.0 and 0.7); Q11- Hands (0.9). The virtual objects are realistic in terms of scale: (relationship among the objects' dimensions) Q12- Chair (0.9); Q13- Patient (0.8 and 0.9); Q14- Bench (0.9); Q15- Tray (0.9 and 0.7); Q16Intermediary device (0.9 and 0.8); Q17- Needle (0.9 and 0.8); Q18- Dry cotton (0.9); Q19- Cotton soaked with alcohol (0.9); Q20- Tourniquet (0,9); Q21- Hands (0.9 and 1.0). The virtual objects are realistic in regard to the model's position in the environment: Q22- Chair (1.0 and 0.9); Q23- Patient (0.9); Q24- Bench (0.9); Q25- Tray (0.9); Q26- Intermediary device (1.0 and 0.9); Q27- Needle (1.0); Q28- Dry cotton (1.0 and 0.9); Q29- Cotton soaked with alcohol (1.0 and 0.9); Q30Tourniquet (0.9); Q31- Hands (0.9 and 1.0); Q32- The number of virtual objects in the environment is sufficient for the proposed simulation (0.9 and 1.0);

Interactive Aspects - Q33- The device movements were precise (relationship between movement, speed of intermediary device/virtual needle and movement) (0.3); Q34- The space available to perform the puncture is sufficient (amplitude of movement during manipulation) (0.7 and 0.9); Q35- Visualization of the environment (immersion environment) is sufficient for the simulation experience (0.9); Q36- The environment where hands actually move to perform the puncture (hands are free) is sufficient for the simulation experience (0.9);

Movement Simulation Reality Aspect - Q37- Place tourniquet on arm (0.5); Q38- Skin asepsis (1.0 and 0.8); Q39- Tight the skin with dominant hand (0.8 and 0.5$)$; Q40- Venipuncture (0.7 and 0.2); Q41- Insert the vacuum tube into the adapter (0.7); Q42- Blood flowing into the tube (0.9); Q43- Release tourniquet from patient's arm (0.6 and 0.5); Q44- Removal of bloodfilled tube from the adapter (0.5); Q45- Homogenization of blood sample (0.7 and 0.9); Q46- Needle removal (0.6 and 0.5); Q47- Compression of the puncture site with cotton (0.9 and 0.7); Q48- Placement of the intermediary device on the tray (0.9 and 0.7);

Teaching Aspect - Q49- An immersive virtual simulation can be a tool to teach the peripheral venipuncture to collect blood samples using a vacuum tube (1.0); Q50- Research addressing immersive virtual simulation can contribute to teaching in the nursing field (1.0); Q51- The immersive environment during simulation contributed to learning the procedure of peripheral venipuncture to collect blood samples using a vacuum tube (1.0);

User-friendly Aspect - Q52- The simulator is userfriendly (0.7); Q53- The simulator is difficult to use (0.4 and 0.3); Q54- The simulator is tiresome (0.1 and 0.3).

Data concerning the participants' occupation and performance are presented in Figures 1 to 3 . 


\begin{tabular}{|c|l|c|l|l|}
\hline & Background & $\begin{array}{c}\text { Time since } \\
\text { graduation }\end{array}$ & \multicolumn{1}{|c|}{ Years in current occupation } & \multicolumn{1}{|c|}{ Previous occupation } \\
\hline $\mathbf{1}$ & Nurse & 30 years & Teaching (12 years) & Care delivery (18 years) \\
\hline $\mathbf{2}$ & Nurse & 8 years & Graduate student & Medical Clinic (3 years) \\
\hline $\mathbf{3}$ & $\begin{array}{l}\text { Biochemical } \\
\text { pharmacist }\end{array}$ & 6 years & Public employee (8 years) & Teaching (10 years) \\
\hline $\mathbf{4}$ & Nurse & 15 years & Teaching (2 years) & Hospital Care (15 years); Intensive Care (6 years) \\
\hline $\mathbf{5}$ & Nurse & 3 years & Graduate student & $\begin{array}{l}\text { Primary healthcare (11 months); Urgency/Trauma } \\
\text { (2 years); Intensive Care (6 months) }\end{array}$ \\
\hline $\mathbf{6}$ & Nurse & 12 years & Graduate student & Care delivery (8 years); Teaching (4 years) \\
\hline $\mathbf{7}$ & Nurse & 6 years & Graduate student; Teaching (2 years) & Pre-hospital care (3 years); Intensive Care (2 years) \\
\hline $\mathbf{8}$ & Nurse & 7 years & Graduate student; Teaching-Administrative (3 years) & Primary Healthcare (2 years) \\
\hline $\mathbf{9}$ & Nurse & 16 years & Teaching (9 years) & Care delivery (7 years) \\
\hline $\mathbf{1 0}$ & Nurse & 15 years & Teaching (12 years) & - \\
\hline $\mathbf{1 1}$ & Nurse & 7 years & Teaching in Family Health (2 years) & Head of a Primary Healthcare Unit (1 year) \\
\hline $\mathbf{1 2}$ & Nurse & 5 years & Graduate student & Care delivery (1 year); Deft interpreter (5 years) \\
\hline $\mathbf{1 3}$ & Nurse & 4 years & Teaching (2 months); Care delivery (1 month) & - \\
\hline $\mathbf{1 4}$ & Nurse & 5 years & Graduate student & Teaching (4 months) \\
\hline $\mathbf{1 5}$ & Nurse & 3 years & Graduate student & \\
\hline
\end{tabular}

Figure 1 - Formal education and occupation of the workers who took part in the VIDA-Nursing V.1.0 Simulation. Ribeirão Preto, SP, Brazil, 2018

\begin{tabular}{|c|c|c|c|c|c|c|c|c|c|c|c|c|c|c|c|c|}
\hline Performance & 1 & 2 & 3 & 4 & 5 & 6 & 7 & 8 & 9 & 10 & 11 & 12 & 13 & 14 & 15 & Total \\
\hline $\begin{array}{l}\text { Duration of } 1^{\text {st }} \\
\text { environment }\end{array}$ & $00^{\prime} 50^{\prime \prime}$ & $01^{\prime} 15^{\prime \prime}$ & $02^{\prime} 25^{\prime \prime}$ & 01'38' & 01'21" & $02^{\prime} 34^{\prime \prime}$ & 01'29" & $05^{\prime} 10^{\prime \prime}$ & 01'52" & $02^{\prime} 25^{\prime \prime}$ & 03'20" & 02'20" & 02'44" & 01'24" & 01'57" & $\begin{array}{c}32^{\prime} 44^{\prime \prime} \\
\left(M^{*}-02^{\prime} 11^{\prime \prime}\right)\end{array}$ \\
\hline $\begin{array}{l}\text { Duration of } \\
\text { simulation }\end{array}$ & 16 '38" & $07 ' 38 "$ & $15^{\prime} 00^{\prime \prime}$ & $20^{\prime} 10^{\prime \prime}$ & $23^{\prime} 53^{\prime \prime}$ & $18^{\prime} 21^{\prime \prime}$ & $08^{\prime} 58^{\prime \prime}$ & $28^{\prime} 49^{\prime \prime}$ & $22^{\prime} 38^{\prime \prime}$ & $11^{\prime} 09^{\prime \prime}$ & $15^{\prime} 48^{\prime \prime}$ & $16^{\prime \prime} 12^{\prime \prime}$ & $19 ' 28 "$ & $10^{\prime} 48^{\prime \prime}$ & $13^{\prime} 47^{\prime \prime}$ & $\begin{array}{c}249^{\prime} 17^{\prime \prime}\left(\mathrm{M}^{*}-\right. \\
\left.16^{\prime} 37^{\prime \prime}\right)\end{array}$ \\
\hline $\begin{array}{l}\text { Duration/first } \\
\text { attempt }\end{array}$ & $\begin{array}{l}6^{\prime} 28^{\prime \prime} \\
/ 11^{\text {th }}\end{array}$ & $\begin{array}{l}07^{\prime} 23^{\prime \prime} \\
12^{\text {nd }} \\
\end{array}$ & $\begin{array}{c}14^{\prime} 31^{\prime \prime} \\
15^{\text {th }} \\
\end{array}$ & $\begin{array}{c}066^{\prime} 58^{\prime \prime} \\
12^{\text {nd }}\end{array}$ & \begin{tabular}{|l}
$20^{\prime} 36^{\prime \prime}$ \\
$/ 11^{\text {th }}$
\end{tabular} & $\begin{array}{l}14^{\prime} 20^{\prime \prime} \\
/ 10^{\text {th }}\end{array}$ & $\begin{array}{c}08^{\prime} 37^{\prime \prime} \\
/ 3^{\text {rd }}\end{array}$ & - & - & \begin{tabular}{|l|}
$05^{\prime} 37^{\prime \prime}$ \\
$12^{\text {nd }}$ \\
\end{tabular} & $\begin{array}{l}11^{\prime} 50^{\prime \prime} \\
15^{\text {th }} \\
\end{array}$ & $\begin{array}{c}066^{\prime} 59^{\prime \prime} \\
12^{\text {nd }}\end{array}$ & $\begin{array}{c}08^{\prime} 51^{\prime \prime} \\
/ 3^{\text {rd }}\end{array}$ & $\begin{array}{c}06^{\prime} 13^{\prime \prime} \\
/ 1^{\text {st }}\end{array}$ & $\begin{array}{c}08^{\prime} 17^{\prime \prime} \\
/ 3^{\text {rd }}\end{array}$ & - \\
\hline $\begin{array}{l}\text { Correct } \\
\text { answers/ } \\
\text { Attempts }\end{array}$ & $1 / 11$ & $1 / 2$ & $1 / 5$ & $4 / 9$ & $2 / 13$ & 2/11 & $1 / 3$ & $0 / 12$ & 0/11 & $2 / 5$ & $2 / 7$ & $3 / 7$ & $3 / 9$ & $2 / 2$ & $2 / 5$ & $\begin{array}{c}26 / 112 \\
\left(\mathrm{M}^{*}-1.7 / 7.5\right) \\
(23.2 \% \\
\text { correct) } \\
\end{array}$ \\
\hline \begin{tabular}{|l|} 
Asked \\
demonstration
\end{tabular} & Yes & No & Yes & No & Yes & Yes & No & Yes & Yes & No & No & No & No & No & No & $6(40 \%)$ \\
\hline $\begin{array}{l}\text { Recently used } \\
\text { Kinect/Xbox }\end{array}$ & No & No & No & No & No & No & No & No & No & No & No & No & No & No & Yes & $1(6.7 \%)$ \\
\hline $\begin{array}{l}\text { Prescription } \\
\text { glasses }\end{array}$ & Yes & No & No & No & No & No & No & No & No & No & No & No & No & Yes & No & 2 (13.3\%) \\
\hline $\begin{array}{l}\text { Right/Left } \\
\text { Handed }\end{array}$ & $\mathrm{R}^{\dagger}$ & $\mathrm{L}^{\ddagger}$ & $R^{\dagger}$ & $\mathrm{R}^{\dagger}$ & $R^{\dagger}$ & $\mathrm{R}^{\dagger}$ & $R^{\dagger}$ & $\mathrm{L}^{\ddagger}$ & $R^{+}$ & $\mathrm{R}^{\dagger}$ & $\mathrm{R}^{\dagger}$ & $\mathrm{L}^{\ddagger}$ & $\mathrm{R}^{+}$ & $\mathrm{R}^{\dagger}$ & $\mathrm{R}^{\dagger}$ & $\begin{array}{c}\mathrm{R}^{\dagger}-12 \\
(80 \%) / \mathrm{L}^{\ddagger}-3 \\
(20 \%)\end{array}$ \\
\hline
\end{tabular}

${ }^{*} \mathrm{M}=$ Mean; ${ }^{+} \mathrm{R}=$ Right handed; ${ }^{\ddagger} \mathrm{L}=$ Left handed

Figure 2 - Performance of the workers who took part in the VIDA-Nursing v.1.0 Simulation. Ribeirão Preto, SP, Brazil, 2018

\begin{tabular}{|c|c|c|c|c|c|c|c|c|c|c|c|c|c|c|c|c|}
\hline Performance & 1 & 2 & 3 & 4 & 5 & 6 & 7 & 8 & 9 & 10 & 11 & 12 & 13 & 14 & 15 & Total \\
\hline $\begin{array}{l}\text { Duration of } 1^{\text {st }} \\
\text { environment }\end{array}$ & $01^{\prime} 25 "$ & $01^{\prime} 04^{\prime \prime}$ & 1'31" & 01'15" & $02^{\prime} 06^{\prime \prime}$ & 02 '45" & 02 '19" & $02^{\prime} 00^{\prime \prime}$ & 03 '30" & $01 ' 25^{\prime \prime}$ & 02 '02" & 01'21" & 01'10" & $01^{\prime} 40^{\prime \prime}$ & $01^{\prime} 45 "$ & $\begin{array}{c}27^{\prime} 18^{\prime \prime}\left(\mathrm{M}^{*}-\right. \\
\left.01^{\prime} 49^{\prime \prime}\right)\end{array}$ \\
\hline $\begin{array}{l}\begin{array}{l}\text { Duration of } \\
\text { simulation }\end{array} \\
\end{array}$ & $10^{\prime} 47^{\prime \prime}$ & $12 ' 55 "$ & ;'00" & $09^{\prime} 16^{\prime \prime}$ & $18^{\prime} 32 "$ & $16{ }^{\prime} 30^{\prime \prime}$ & $25^{\prime} 37^{\prime \prime}$ & $20 ' 37 "$ & 17'09" & $22^{\prime} 22^{\prime \prime}$ & 08'52" & $37^{\prime} 00^{\prime \prime}$ & $16^{\prime} 09^{\prime \prime}$ & $06 ' 29 "$ & $44^{\prime} 49^{\prime \prime}$ & $\begin{array}{c}255^{\prime} 04^{\prime \prime}\left(\mathrm{M}^{*}-\right. \\
\left.17^{\prime} 00^{\prime \prime}\right)\end{array}$ \\
\hline $\begin{array}{l}\text { Duration/first } \\
\text { attempt }\end{array}$ & $\begin{array}{c}10^{\prime} 35^{\prime \prime} \\
14^{\mathrm{a}}\end{array}$ & $\begin{array}{c}12^{\prime} 41^{\prime \prime} \\
17^{a}\end{array}$ & $\begin{array}{c}06^{\prime} 12^{\prime \prime} \\
12^{\mathrm{a}}\end{array}$ & \begin{tabular}{|c|}
$06^{\prime} 32^{\prime \prime}$ \\
$13^{\mathrm{a}}$
\end{tabular} & $\begin{array}{c}08^{\prime} 57^{\prime \prime} \\
13^{\mathrm{a}}\end{array}$ & $\begin{array}{c}07^{\prime} 04^{\prime \prime} \\
/ 1^{a}\end{array}$ & $\begin{array}{c}09^{\prime} 08^{\prime \prime} \\
13^{a}\end{array}$ & $\begin{array}{c}18^{\prime} 17^{\prime \prime} \\
19^{a}\end{array}$ & $\begin{array}{c}14^{\prime} 09^{\prime \prime} \\
17^{a}\end{array}$ & $\begin{array}{l}06^{\prime} 50^{\prime \prime} \\
15^{\mathrm{a}}\end{array}$ & $\begin{array}{c}06^{\prime} 53^{\prime \prime} \\
/ 3^{a}\end{array}$ & $\begin{array}{l}30^{\prime} 43^{\prime \prime} \\
/ 18^{a}\end{array}$ & $\begin{array}{c}04^{\prime} 29^{\prime \prime} \\
/ 1^{a}\end{array}$ & $\begin{array}{c}05^{\prime} 51^{\prime \prime} \\
/ 2^{a}\end{array}$ & \begin{tabular}{|c|}
$24^{\prime} 39^{\prime \prime}$ \\
$/ 19^{a}$
\end{tabular} & 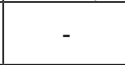 \\
\hline $\begin{array}{l}\text { Correct } \\
\text { answers/ } \\
\text { Attempts }\end{array}$ & $1 / 4$ & $1 / 7$ & $2 / 3$ & $2 / 5$ & $3 / 12$ & $4 / 5$ & $3 / 15$ & $1 / 11$ & $2 / 9$ & $10 / 23$ & $2 / 4$ & $2 / 21$ & $2 / 8$ & $1 / 2$ & $1 / 19$ & $\begin{array}{c}37 / 148 \\
\left(\mathrm{M}^{*}-2.5 / 9.9\right) \\
(25 \% \\
\text { correct } \\
\text { answers }) \\
\end{array}$ \\
\hline \begin{tabular}{|l|} 
Asked \\
demonstration
\end{tabular} & Yes & Yes & No & No & No & No & No & Yes & Yes & No & No & Yes & No & No & Yes & $6(40 \%)$ \\
\hline $\begin{array}{l}\text { Recently used } \\
\text { Kinect/Xbox }\end{array}$ & No & No & Yes & No & No & No & No & Yes & No & Yes & Yes & Yes & Yes & No & No & $6(40 \%)$ \\
\hline \begin{tabular}{|l}
$\begin{array}{l}\text { Prescription } \\
\text { glasses }\end{array}$ \\
\end{tabular} & Yes & Yes & No & No & Yes & No & No & No & No & No & Yes & No & No & No & No & 4 26.7\%) \\
\hline $\begin{array}{l}\text { Right/Left } \\
\text { Handed }\end{array}$ & $\mathrm{R}^{\dagger}$ & $\mathrm{L}^{\ddagger}$ & $R^{\dagger}$ & $\mathrm{R}^{\dagger}$ & $\mathrm{L}^{\ddagger}$ & $R^{\dagger}$ & $\mathrm{R}^{\dagger}$ & $\mathrm{R}^{\dagger}$ & $\mathrm{R}^{\dagger}$ & $\mathrm{R}^{\dagger}$ & $\mathrm{R}^{\dagger}$ & $\mathrm{R}^{\dagger}$ & $\mathrm{R}^{\dagger}$ & $\mathrm{R}^{\dagger}$ & $\mathrm{R}^{\dagger}$ & $\begin{array}{c}\mathrm{R}^{\dagger} 13 \\
(86.7 \%) / \\
\mathrm{L}^{\ddagger}-2 \\
(13.3 \%) \\
\end{array}$ \\
\hline Semester & $8^{\text {th }}$ & $8^{\text {th }}$ & $8^{\text {th }}$ & $8^{\text {th }}$ & $8^{\text {th }}$ & $8^{\text {th }}$ & $8^{\text {th }}$ & $8^{\text {th }}$ & $8^{\text {th }}$ & $8^{\text {th }}$ & $4^{\text {th }}$ & $4^{\text {th }}$ & $6^{\text {th }}$ & $7^{\text {th }}$ & $10^{\text {th }}$ & - \\
\hline
\end{tabular}

${ }^{*} \mathrm{M}=$ Média; ${ }^{+} \mathrm{D}=$ Destro; ${ }^{\ddagger} \mathrm{S}=$ Sinistro

Figure 3 - Performance of the undergraduate students who took part in the VIDA-Nursing v.1.0 Simulation. Ribeirão Preto, SP, Brazil, 2018 
The configuration of the equipment used in the simulation, initial screen, ambience setting, material, and procedure are portrayed in Figure 4.
The workers assessing the VIDA-Nursing v1.0 simulator considered $79.6 \%$ of the assessed items to be valid, while the students considered $66.7 \%$ of the items valid.
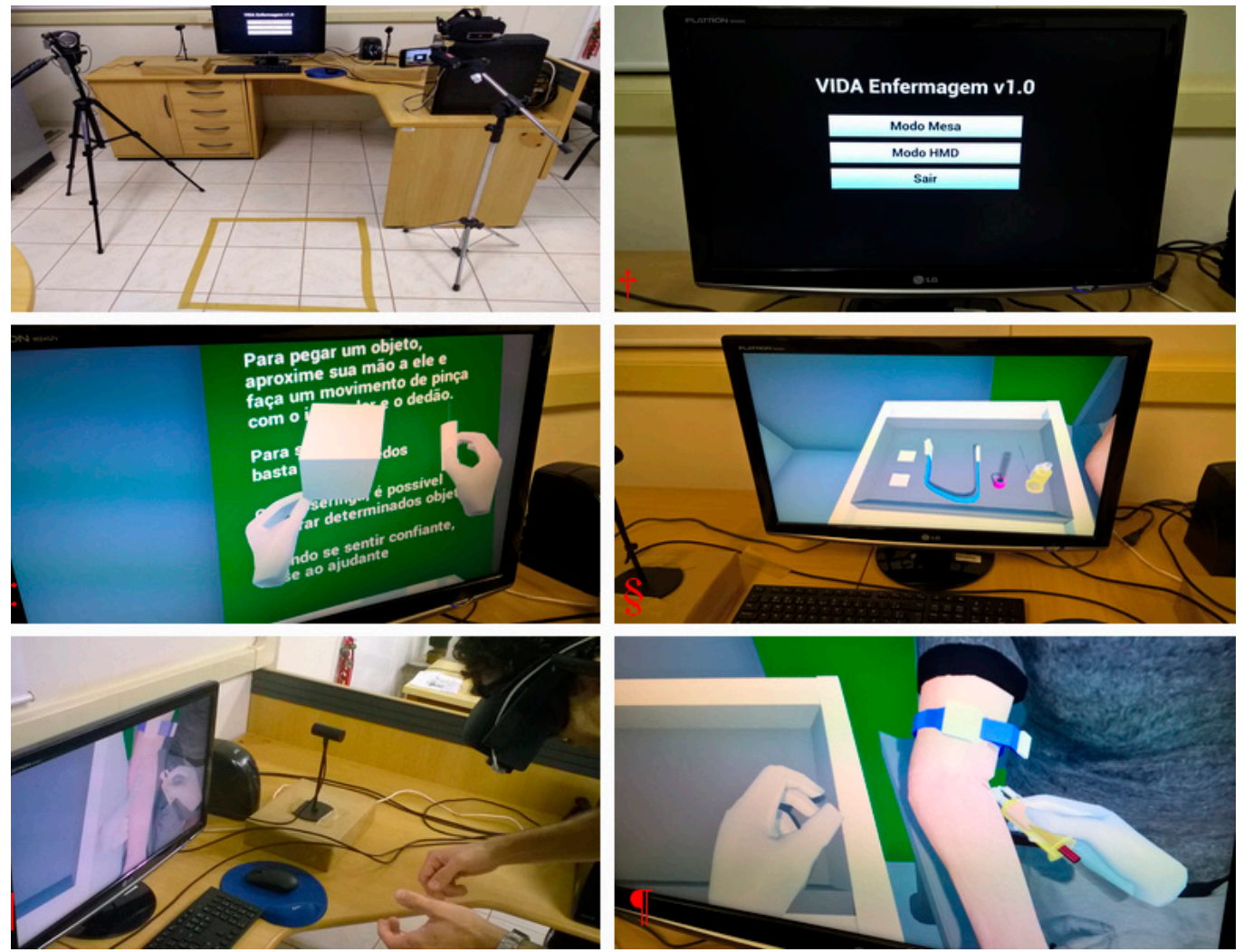

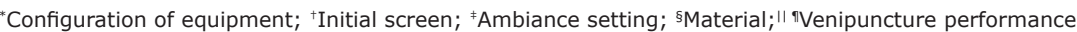

Figure 4 - VIDA-Nursing v1.0

\section{Discussion}

Technological resources in the teaching of nursing are developing constantly, however, the use of immersive VR simulation in the implementation of these strategies is seldom explored. One study analyzing the contributions of digital educational technologies in the teaching of nursing, reports that only two (6.7\%) out of 30 studies involved the use of virtual reality(51).

An analysis of the literature ${ }^{(52)}$ addressing strategies used in the teaching of the peripheral venipuncture procedure identified three simulations developed with VR, without using immersion resources: Virtual I.V. simulator (Laerdal Medical), CathYes AccuTouch System simulator (Immersion Medical, Inc.), and IV SIM simulator (ARvision, Daejeon, Republic of Korea). Most of these studies report positive results in the use of simulators, though, those comparing traditional methods with virtual simulators did not present significant results but show that the combination of strategies, that is, virtual simulations with traditional methods, is indicated for the teaching of the peripheral venipuncture procedure. These simulators have a haptic unit in which users perform the peripheral venipuncture and see the result in computer virtual simulation. The haptic unit is an interesting resource for tactile interaction during simulations, however, these simulators, in addition to being costly, employ a mouse during part of the interaction.

The Leap Motion gesture sensor associated with HMD Oculus Rift was used in the development of the VIDA-Nursing v1.0 simulator. The gesture sensor is a screening device that captures the movement of hands and fingers with high precision ${ }^{(53)}$. The Head-mounted Display (HMD) enables the total immersion of users in an artificial environment through two liquid crystal displays that allow for stereoscopic vision ${ }^{(13)}$. Using these devices together is beneficial to facilitate programming and also because of the great potential of these two devices when used together with the sensor system and users' immersion. Having the hands free to manipulate objects in the virtual environment and reproducing the environment with stereoscopy visualization using HMD allows users to experience a very realistic artificial world, an essential characteristic to develop hand-eye coordination that is part of most invasive procedures used in the health field. 
In general, the VIDA-Nursing v1.0 simulator was considered a valid and promising tool to teach the procedure of vacuum blood collection in adults among undergraduate nursing students being introduced to this subject and technique. This simulator is expected to be used to teach this procedure after implementing suggestions and improvements needed for future versions. Studies addressing the development of immersive VR strategies have reported positive results in the field of teaching in the health field, especially in the training of specific procedures ${ }^{(41,54)}$.

In the workers' assessment, nine items in the Movement Simulation Reality Aspect were considered to require revision (Q33, Q34, Q37, Q40, Q41, Q43, Q44, $\mathrm{Q} 45$ and Q46). The assessment concerning the Userfriendly Aspect shows that two items (Q52 and Q53) need to be revised, while item Q54 was well rated.

The students' assessment shows that 18 items require revision, five are related to the Visual Aspect (Q7, Q8, Q9, Q10, and Q15), one item in the Interactive Aspect (Q33), nine items in the Movement Simulation Reality Aspect (Q37, Q39, Q40, Q41, Q43, Q44, Q46, $\mathrm{Q} 47$, and $\mathrm{Q} 48$ ) and three items in the User-friendly Aspect (Q52, Q53, and Q54).

The items in the Visual Aspect, which according to the students, require review $(\mathrm{Q} 7, \mathrm{Q} 8, \mathrm{Q} 9, \mathrm{Q} 10$, and Q15), that is, Difficulty in visualizing the needle (Q7), Dry cotton (Q8) and Cotton soaked with alcohol (Q9), may be related to the system's limited resolution, especially concerning the needle bevel. We believe this assessment may have been influenced by the fact that four students wore prescription glasses to see nearby objects. The workers, however, did not consider necessary to review any items in the Visual Aspect. Oculus Rift has a limitation for those wearing prescription glasses to correct hyperopia and a strategy to minimize users' difficulty of visualization is to use a simulator version in which objects are presented on a scale larger than reality. The students were not familiar with the model of the tourniquet (Q10) used in the simulator and some students perceived the Tray (Q15) to be larger than reality. All these items can be improved by refining the modeling of virtual objects. Additionally, configuring the simulator according to each participant's height before beginning the simulation can also better meet the specificities of users.

The items in the Interactive Aspect that need revision include the precision of the device's movements (Q33), the space required to perform the puncture movement (Q34), Vein puncture (Q40), Insertion of the vacuum tube into the adapter (Q41), Removal of the blood-filled tube from the adapter (Q44), Needle removal (Q46), Compression of the puncture site with cotton (Q47), and Placement of the intermediate on the tray (Q48). All the items are related to difficulties in performing fine movements (at the time of puncturing the vein and manipulating objects) and configuration of the space at the time of the puncture. These may be related to a limitation of the Leap Motion to capture some movements if their configuration is not well standardized $^{(53)}$. There are, however, ways to improve the system's calibration, such as modeling a larger caliber vein to facilitate the access of users and minimize the problem.

The item Space to move at the time of performing the puncture (Q34) generated doubts among some participants, even though details were provided in the assessment form and during the experiment. This item refers to the space available for the participants to move around physically, however, some participants understood it referred to the virtual environment. Therefore, this item will be revised.

Regarding the Movement Reality Simulation Aspect, improvements were suggested to the items that refer to the Arm tourniquet (Q37 and Q43), which in this first experiment was programed to be performed with one of the hands only and will be reconfigured for two hands. Additionally, Tighten skin with the non-dominant hand (Q39) was restricted to one site restricting the puncture area. Assessment of the Homogenization of the blood sample (Q45) suggests that the blood inside the tube follows the rotating movement of the tube. Suggestions for the Compression of puncture site with cotton (Q47) and Placement of the intermediate on the tray (Q48) are that blood drips from the site in case it is not sufficiently compressed and that the intermediate does not return positioned with the needle upward, as it does at the beginning of the simulation; rather it should appear lying on the tray or with the possibility of being discarded into a sharp container. Another measure to improve these stages is the configuration of the structures in the virtual environment so that there is no overlap among them, hence users do not visualize one object entering another.

The implementation of the improvements previously mentioned is expected to solve the issues in the Userfriendly Aspect (Q52, Q53, and Q54). Other options to make the simulator more user-friendly include: making a version for left-handed users or enable them to be free to choose their left or right hand at the time of tightening the skin when performing the puncture procedure. The system in this current version recognizes the left hand tightening the skin and if a left-handed user tights the skin with the right hand and punctures the vein with the left hand, the system indicates hands are inverted and impedes the simulation to continue. Left-handed participants performed the simulation with their right 
hands. Only one, out of the five left-handed participants, did not complete the procedure, showing the simulator is easy to use and will be useful for undergraduate nursing students to learn the technique.

One of the aspects to be considered in the use of teaching technologies is how much technology is currently present in people's lives. Between the two groups, workers reported having less frequent contact with VR devices while some students reported having previously used these devices applied in teaching settings, which may have influenced the groups' performance and interest in participating and assessing the simulator.

Only two, out of the 30 participants were not able to complete the procedure though these were workers who draw blood samples using a vacuum tube almost daily. The workers with extensive professional experience who do not perform this procedure daily were able to perform the simulation more easily; similar to those who had no practice in the technique, as was the case of the students.

Because the group of more experienced workers had performed this procedure numerous times, they wanted to see a simulation of patients' behavior (especially verbal communication) in addition to the procedure, to be also rapid and individualized, considering that each worker has a specific manner to perform the procedure according to recommended guidelines. When we analyze operant behavior, as proposed by Skinner ${ }^{(49)}$, lack of behavior in the simulator, as workers expected, generated a negative reinforcement, that is, they were not supported to carry on with the procedure. For students or inexperienced workers, facing difficulties to complete the simulation up to its end was positive reinforcement, a challenge for the users to end the simulation only after completing all the stages. Additionally, the less experienced, the greater the positive reinforcement on one's behavior to complete the procedure, as students' scores show. The students' mean number of correct answers was higher ( 2.5 correct answers/9.9 attempts) than that obtained by the workers (1.7 correct answers/7.5 attempts). Another operant behavior response was that the longer a participant interacted with the simulator, the better his/her performance concerning the duration of use.

In addition to the various possibilities to make the simulator a more interactive and motivating tool among students, there are the priority items that need to be addressed in the next version: to add new devices to make the virtual simulation environment more adaptable to the students' environment such as the use of prescription glasses with the immersion device for those who need vision correction and adjust the system to be used by both left- and right-handed individuals. These and other improvements can be addressed in future versions as this study progresses and new demands and opportunities are identified.

Feedback will be provided to users in the simulator's final version at the end of the simulation, presenting adverse events that took place during the procedure to promote a positive reinforcement for the learning of users. Even though the current version provides little feedbacks to users, promising effects of positive reinforcement were identified during its use.

Among this study's potential biases and limitations, there is the fact that data collection indicated that, at the end of the day, the gesture sensor seemed to have its performance decreased, requiring pauses between simulations to improve its performance. The assessment form was considered comprehensive but required time and attention from the participants during its completion. Having left-handed participants as well as individuals wearing prescription glasses to be able to see nearby objects - without previously adapting the system - may have influenced how these individuals' assessed the simulator. These limitations had not been foreseen.

\section{Conclusion}

The development of the VIDA-Nursing v1.0 simulator revealed that obtaining a complete procedure simulator is a complex task. Numerous technological resources need to be used and incorporated during its implementation, which will be only achieved in the course of this study, by testing and improving research, so that we will be able to achieve a final product that can be incorporated as a teaching resource in nursing schools and meet the needs of this target population regarding the learning of this procedure.

The 14 steps performed during the simulation were assessed through 54 items. Even though according to the participants, approximately one-third of the items required revision, the VIDA-Nursing v1.0 simulator was considered a promising tool to teach the procedure of blood collection using a vacuum tube in adult patients. The reason is mainly that it can be combined with resources currently used to teach this procedure to undergraduate nursing students and therefore, provide better training to students so they develop the competencies needed to care for patients during supervised training and later, in their professional practice.

\section{References}

1. Vizcarra C, Cassutt C, Corbitt N, Richardson D, Runde D, Stafford K. Recommendations for improving 
safety practices with short peripheral catheters. J Infus Nurs. 2014 Mar-Apr;37(2):121-4. doi: 10.1097/ NAN.0000000000000028.

2. Gorski LA, Hadaway L, Hagle M, McGoldrick M, Orr M, Doellman D. 2016 Infusion therapy standards of practice. J Infus Nurs. [Internet]. 2016 [cited Jun 10, 2018];39(1 Suppl.):S1-S159. Available from: https://www.ins1. org/Store/ProductDetails. aspx?productId=113266

3. Royal College of Nursing. Standards for infusion therapy. Fourth edition. RCN. [Internet]. 2016 [cited Nov 20, 2017]. Available from: https://www.rcn.org.uk/ professional-development/publications/pub-005704

4. Cicolini G, Manzoli L, Simonetti V, Flacco ME, Comparcini D, Capasso $L$, et al. Phlebitis risk varies by peripheral venous catheter site and increases after 96 hours: a large multi-centre prospective study. J Adv Nurs. 2014 Nov;70(11):2539-49. doi: 10.1111/ jan. 12403.

5. Wallis MC, McGrail M, Webster J, Marsh N, Gowardman J, Playford EG, et al. Risk factors for peripheral intravenous catheter failure: a multivariate analysis of data from a randomized controlled trial. Infect Control Hosp Epidemiol. 2014 Jan;35(1):63-8. doi: $10.1086 / 674398$.

6. Danski MTR, Johann DA, Vayego SA, Oliveira GRL, Lind J. Complications related to the use of peripheral venous catheters: a randomized clinical trial. Acta Paul. Enferm. 2016 Feb;29(1):84-92. doi: 10.1590/19820194201600012.

7. Sato A, Nakamura I, Fujita H, Tsukimori A, Kobayashi $\mathrm{T}$, Fukushima $\mathrm{S}$, et al. Peripheral venous catheterrelated bloodstream infection is associated with severe complications and potential death: a retrospective observational study. BMC Infect Dis. 2017 Jun 17;17(1):434. doi: 10.1186/s12879-017-2536-0.

8. Sociedade Brasileira de Patologia Clínica/Medicina Laboratorial. Recomendações da Sociedade Brasileira de Patologia Clínica/Medicina Laboratorial (SBPC/ML): coleta e preparo da amostra biológica. [Internet]. Barueri, SP: Manole; 2014. [Acesso em 5 abr 2018]. Disponível em: http://www.sbpc.org.br/upload/ conteudo/livro_coleta_biologica2013.pdf

9. Plebani M, Sciacovelli L, Aita A, Chiozza ML. Harmonization of pre-analytical quality indicators. Biochem Med. (Zagreb). 2014 Feb;15;24(1):105-13. doi: 10.11613/BM.2014.012.

10. Cadamuro J, von Meyer A, Wiedemann $H$, Klaus Felder T, Moser F, Kipman $U$, et al. Hemolysis rates in blood samples: differences between blood collected by clinicians and nurses and the effect of phlebotomy training. Clin Chem Lab Med. 2016 Dec 1;54(12):1987-92. doi: $10.1515 / \mathrm{cclm}-2016-0175$.
11. Lippi G, von Meyer A, Cadamuro J, Simundic AM. Blood sample quality. Diagnosis. (Berl). 2019 Mar 26;6(1):25-31. doi: $10.1515 / \mathrm{dx}-2018-0018$.

12. Martins JCA, Mazzo A, Baptista RCN, Coutinho VRD, Godoy S, Mendes IAC, et al. The simulated clinical experience in nursing education: a historical review. Acta Paul Enferm. 2012;25(4):619-25. doi: 10.1590/ S0103-21002012000400022.

13. Tori R, Hounsell MS, Kirner C. Realidade Virtual. In: Tori R, Hounsell M (Org). Introdução a Realidade Virtual e Aumentada. [Internet]. Porto Alegre: Editora SBC; 2018. [Acesso 25 nov 2018]; cap. 1, p. 9-25. Disponível em: http://www.de.ufpb.br/ labteve/publi/2018_livroRVA.pdf 14. Tori $R$, Kirner C. Fundamentos de realidade virtual. In: Tori R, Kirner C, Siscoutto R. (Eds). Fundamentos e tecnologia de realidade virtual e aumentada. Editora SBC. [Internet]. 2006 [acesso em 25 nov, 2018]; cap 1., p. 2-58. Disponível em: http://www.ckirner.com/ download/capitulos/Fundamentos_e_Tecnologia_de_ Realidade_Virtual_e_Aumentada-v22-11-06.pdf 15. Brunner I, Skouen JS, Hofstad H, Aßmuss J, Becker $\mathrm{F}$, Pallesen $\mathrm{H}$, et al. Is upper limb virtual reality training more intensive than conventional training for patients in the subacute phase after stroke? An analysis of treatment intensity and content. BMC Neurol. 2016 Nov 11;16(1):219. doi: 10.1186/s12883-016-0740-y.

16. Faria AL, Andrade A, Soares L, I Badia SB. Benefits of virtual reality based ceognitive rehabilitation through simulated activities of daily living: a randomized controlled trial with stroke patients. J Neuroeng Rehabil. 2016 Nov 2;13(1):96. doi: 10.1186/s12984-016-0204-z. 17. Lendvay TS, Brand TC, White L, Kowalewski T, Jonnadula $S$, Mercer LD, et al. Virtual reality robotic surgery warm-up improves task performance in a dry laboratory environment: a prospective randomized controlled study. J Am Coll Surg. 2013 Jun;216(6):1181-92. doi: 10.1016/j.jamcollsurg.2013.02.012.

18. Bartlett RD, Radenkovic D, Mitrasinovic S, Cole A, Pavkovic I, Denn PCP, et al. A pilot study to assess the utility of a freely downloadable mobile application simulator for undergraduate clinical skills training: a single-blinded, randomised controlled trial. BMC Med Educ. 2017 Dec 11;17(1):247. doi: 10.1186/s12909017-1085-y.

19. Nilsson C, Sorensen JL, Konge L, Westen M, Stadeager $M$, Ottesen $B$, et al. Simulation-based camera navigation training in laparoscopy-a randomized trial. Surg Endosc. 2017;31(5):2131-9. doi: 10.1007/ s00464-016-5210-5.

20. Yiasemidou M, de Siqueira J, Tomlinson J, Glassman D, Stock S, Gough M. "Take-home" box trainers are an effective alternative to virtual reality simulators. 
J Surg Res. 2017 Jun 1;213:69-74. doi: 10.1016/j. jss.2017.02.038.

21. Courteille O, Fahlstedt M, Ho J, Hedman L, Fors U, von Holst $\mathrm{H}$, et al. Learning through a virtual patient vs. recorded lecture: a comparison of knowledge retention in a trauma case. Int J Med Educ. 2018;9:86-92. doi: 10.5116/ijme.5aa3.ccf2.

22. Fu Y, Cavuoto L, Qi D, Panneerselvam K, Yang G, Artikala VS, et al. Validation of a virtual intracorporeal suturing simulator. Surg Endosc. 2018 Oct 17. doi: 10.1007/s00464-018-6531-3.

23. Savran MM, Nielsen AB, Poulsen BB, Thorsen PB, Konge L. Using virtual-reality simulation to ensure basic competence in hysteroscopy. Surg Endosc. 2019 Jul;33(7):2162-8. doi: 10.1007/s00464-018-6495-3.

24. Gibbons EM, Thomson AN, de Noronha M, Joseph S. Are virtual reality technologies effective in improving lower limb outcomes for patients following stroke - a systematic review with meta-analysis. Top Stroke Rehabil. 2016 Dec;23(6):440-57. doi: 10.1080/10749357.2016.1183349. 25. de Rooij IJ, van de Port IG, Meijer JG. Effect of virtual reality training on balance and gait ability in patients with stroke: systematic review and meta-analysis. Phys Ther. 2016 Dec;96(12):1905-18. doi:10.2522/ptj.20160054. 26. Neguț A, Matu SA, Sava FA, David D. Virtual reality measures in neuropsychological assessment: a metaanalytic review. Clin Neuropsychol. 2016 Feb;30(2):165-84. doi: 10.1080/13854046.2016.1144793.

27. Donath L, Rössler R, Faude O. Effects of Virtual Reality Training (Exergaming) Compared to Alternative Exercise Training and Passive Control on Standing Balance and Functional Mobility in Healthy Community-Dwelling Seniors: A Meta-Analytical Review. Sports Med. 2016 Sep;46(9):1293-309. doi: 10.1007/s40279-016-0485-1. 28. Pericot-Valverde I, Germeroth LJ, Tiffany ST. The Use of Virtual Reality in the Production of Cue-Specific Craving for Cigarettes: A Meta-Analysis. Nicotine Tob Res. 2016 May;18(5):538-46. doi: 10.1093/ntr/ntv216. 29. Neri SG, Cardoso JR, Cruz L, Lima RM, de Oliveira $R J$, Iversen $M D$, et al. Do virtual reality games improve mobility skills and balance measurements in communitydwelling older adults? Systematic review and metaanalysis. Clin Rehabil. 2017 Oct;31(10):1292-304. doi: 10.1177/0269215517694677.

30. Iruthayarajah J, McIntyre A, Cotoi A, Macaluso S, Teasell $R$. The use of virtual reality for balance among individuals with chronic stroke: a systematic review and meta-analysis. TopStrokeRehabil. 2017Jan;24(1):68-79. doi: 10.1080/10749357.2016.1192361

31. Booth ATC, Buizer AI, Meyns P, Oude Lansink ILB, Steenbrink F, van der Krogt MM. The efficacy of functional gait training in children and young adults with cerebral palsy: a systematic review and meta-analysis.
Dev Med Child Neurol. 2018 Sep;60(9):866-83. doi: 10.1111/dmcn.13708.

32. Carl E, Stein AT, Levihn-Coon A, Pogue JR, Rothbaum $B$, Emmelkamp $P$, et al. Virtual reality exposure therapy for anxiety and related disorders: A meta-analysis of randomized controlled trials. J Anxiety Disord. 2019 Jan;61:27-36. doi: 10.1016/j.janxdis.2018.08.003.

33. Fernández-Álvarez J, Rozental A, Carlbring $P$, Colombo D, Riva G, Anderson PL, et al. Deterioration rates in Virtual Reality Therapy: An individual patient data level meta-analysis. J Anxiety Disord. 2019 Jan;61:3-17. doi: 10.1016/j.janxdis.2018.06.005.

34. Chan E, Foster S, Sambell R, Leong P. Clinical efficacy of virtual reality for acute procedural pain management: A systematic review and meta-analysis. PLoS One. 2018 Jul 27;13(7):e0200987. doi: 10.1371/ journal.pone.0200987.

35. Fodor LA, Coteț CD, Cuijpers P, Szamoskozi Ș, David $D$, Cristea IA. The effectiveness of virtual reality based interventions for symptoms of anxiety and depression: A meta-analysis. Sci Rep. 2018 Jul 9;8(1):10323. doi: 10.1038/s41598-018-28113-6.

36. Casuso-Holgado MJ, Martín-Valero R, Carazo AF, Medrano-Sánchez EM, Cortés-Vega MD, MonteroBancalero FJ. Effectiveness of virtual reality training for balance and gait rehabilitation in people with multiple sclerosis: a systematic review and metaanalysis. Clin Rehabil. 2018 Sep;32(9):1220-34. doi: 10.1177/0269215518768084.

37. Aminov A, Rogers JM, Middleton S, Caeyenberghs K, Wilson $\mathrm{PH}$. What do randomized controlled trials say about virtual rehabilitation in stroke? A systematic literature review and meta-analysis of upper-limb and cognitive outcomes. J Neuroeng Rehabil. 2018 Mar 27;15(1):29. doi: 10.1186/s12984-018-0370-2.

38. Chen $Y$, Fanchiang HD, Howard A. Effectiveness of Virtual Reality in Children With Cerebral Palsy: A Systematic Review and Meta-Analysis of Randomized Controlled Trials. Phys Ther. 2018 Jan 1;98(1):63-77. doi: $10.1093 / p t j / p z x 107$.

39. Alaker M, Wynn GR, Arulampalam T. Virtual reality training in laparoscopic surgery: A systematic review \& meta-analysis. Int J Surg. 2016 May;29:85-94. doi: 10.1016/j.ijsu.2016.03.034.

40. Lui JT, Hoy MY. Evaluating the effect of virtual reality temporal bone simulation on mastoidectomy performance: a meta-analysis. Otolaryngol Head Neck Surg. 2017 Jun;156(6):1018-24. doi: 10.1177/0194599817698440.

41. Tori R, Wang GZ, Sallaberry LH, Tori AA, Oliveira EC, Machado MAAM. VIDA ODONTO: Virtual Reality Environment for Dental Training. [Portuguese]. RBIE. 2018;26(2):80. doi: 10.5753/rbie.2018.26.02.80. 
42. World Health Organization (WHO). WHO guidelines on drawing blood: best practices in phlebotomy. [Internet]. Geneva: World Health Organization; 2010 [cited Jun 10, 2018]. Available from: https://www.who.int/infectionprevention/publications/drawing_blood_best/en/

43. Potter PA, Perry AG, Stockert P, Hall A. Fundamentals of Nursing. 9th Edition. St. Louis: Elsevier Inc., 2017.

44. Adobe Systems Incorporated. Copyright (c) 2019 Adobe Systems Incorporated. Available from: www. mixamo.com

45. Alexandre NMC, Coluci MZO. Content validity in the development and adaptation processes of measurement instruments. [Portuguese]. Ciênc Saúde Coletiva. 2011 July;16(7):3061-8. doi: 10.1590/S141381232011000800006.

46. Polit DF, Beck CT. Nursing Research: Generating and Assessing Evidence for Nursing Practice. Ninth Edition. Philadelphia: Wolters Kluwer Health/Lippincott Williams \& Wilkins; 2012.

47. Ang CS, Avni E, Zaphiris P. Linking Pedagogical Theory of Computer Games to Their Usability. Int ] E-Learning. [Internet]. 2008 [cited Dec 16, 2019];7(3):533-58. Available from: http://ktisis.cut. ac.cy/bitstream/10488/5160/6/Ang2008-Linking_ Pedagogical_Theory_of_Computer_Games_to_their_ Usability.pdf

48. Nagle A, Wolf $P$, Riener $R$, Novak D. The use of player-centered positive reinforcement to schedule ingame rewards increases enjoyment and performance in a serious game. IJSG. Oct 2014;1(4). doi: 10.17083/ ijsg.v1i4.47.

49. Slussareff $M$, Braad E, Wilkinson $P$, Strååt B. Games for Learning. In: Dörner R, Göbel S, Kickmeier-Rust M, Masuch M, Zweig KA, editors. Entertainment Computing and Serious Games. Gewerbestrasse: Springer International Publishing AG; 2016 p. 189-211.

50. Skinner BF. Selection by consequences. Science. 1981 Jul 31;213(4507):501-4. doi: 10.1126/ science. 7244649 .

51. Silveira M, Cogo ALP. The contributions of digital technologies in the teaching of nursing skills: an integrative review. Rev Gaúcha Enferm. 2017;38(2):e66204. doi: 10.1590/1983-1447.2017.02.66204

52. Souza-Junior VD, Mendes IAC, Marchi-Alves LM, Jackman D, Wilson-Keates B, de Godoy S. Peripheral Venipuncture Education Strategies for Nursing Students. J Infus Nurs. 2020;43(1): Forthcoming.

Corresponding author:

Simone de Godoy

E-mail: sig@eerp.usp.br

(iD_https://orcid.org/0000-0003-0020-7645
53. Costa RM, Kayatt P, Bogoni T. Hardware. In: Tori R, Hounsell M (Org). Introdução a Realidade Virtual e Aumentada. [Internet]. Porto Alegre: Editora SBC; 2018. cap. 5, p. 77-86. [Acesso 25 nov 2018]. Disponível em: http://www.de.ufpb.br/ labteve/publi/2018_livroRVA.pdf 54. Corrêa CG, Machado MAAM, Ranzini E, Tori R, Nunes FLS. Virtual Reality simulator for dental anesthesia training in the inferior alveolar nerve block. J Appl Oral Sci. 2017 Jul-Aug;25(4):357-66. doi: 10.1590/16787757-2016-0386.
Received: May 26 2019 Accepted: Dec 23 2019

Associate Editor: Maria Lúcia Zanetti

Copyright $\odot 2020$ Revista Latino-Americana de Enfermagem This is an Open Access article distributed under the terms of the Creative Commons (CC BY).

This license lets others distribute, remix, tweak, and build upon your work, even commercially, as long as they credit you for the original creation. This is the most accommodating of licenses offered. Recommended for maximum dissemination and use of licensed materials. 